\title{
A FORÇA DA PALAVRA EM CLARICE LISPECTOR E MIA COUTO: HUMANIZAÇÃO E PREVISÃO
}

\author{
Gabriela de Castro Maciel Oliveira \\ Graduanda em Letras e Literaturas de Língua Portuguesa pela Universidade Federal \\ Fluminense (UFF) \\ belikovgabi@gmail.com \\ Maria da Conceição Vinciprova Fonseca \\ Doutora em Letras pela Universidade Federal Fluminense (UFF) \\ Professora do Centro Universitário de Volta Redonda (UniFOA) \\ concyvf@uol.com.br
}

\section{RESUMO}

Este estudo traz evidências da força da palavra aproximando as obras Terra sonâmbula, de Mia Couto, e A hora da estrela, de Clarice Lispector. Feita a leitura das obras, são aqui trazidas categorias comuns em que essa força se manifesta em recortes. A relevância do estudo se dá diante da necessidade de valorizar o coletivo na cultura africana, enquanto força um olhar sobre o indivíduo marginalizado, personificado em Macabéa. A literatura comparada permite a valorização da própria literatura, trazendo à luz um viés social semelhante ao cotidiano de marginalização de muitos alunos. O verbo como fonte criadora permite a criação e recriação da realidade, a reafirmação de si mesmo e de uma identidade cultural, e a representação de um coletivo. A palavra constitui um poder, não só como instrumento de ascensão social, mas oferecendo domínio sobre si mesmo e o mundo, como faltava em Macabéa.

Palavras-chave: Força da palavra; Mia Couto; Clarice Lispector; literatura comparada.

\section{ABSTRACT}

This study provides evidence of the power of the word approaching Mia Couto's Terra sonâmbula and Clarice Lispector's A hora da estrela. After reading the works, com-mon categories in which this force manifests itself are brought here in clippings. The relevance of the study lies in the need to value the collective in African culture, while forcing a look at the marginalized individual, personified in Clarice's Macabéa. Comparative literature allows the valorization of literature itself, bringing to light a social view similar to the daily marginalization of many students. The verb as a source of creation allows the recreation of reality, the reaffirmation of oneself and a cultural identity, and the representation of a collective. The word constitutes a power, not only as an instrument of social ascension, but offering self-confidence and understanding of the world, as was lacking in Macabéa.

Keywords: Word strength; Mia Couto; Clarice Lispector; comparative literature. 


\section{Introdução}

Este trabalho parte de uma pesquisa que investigou a força de criação da palavra como um conceito que aproxima a literatura de Clarice Lispector da produção literária africana em língua portuguesa. Neste estudo, pretende-se demonstrar evidências da força vital e de criação da palavra, aproximando as obras Terra sonâmbula, de Mia Couto, e A hora da estrela, de Clarice Lispector, evidenciando essa força como criadora de realidades e significados e catalizadora de sentimentos que conduzem à ação dos personagens. Os personagens se configuram como sujeitos agentes por meio da linguagem, em locais e tempos diversos, sempre pela força da palavra.

Tal noção da palavra vem traduzir o verbo como fonte de criação e faz compreender de que forma a palavra permite a criação e recriação da realidade e a reafirmação de si mesmo, o que acontece em Clarice Lispector; ou representação de um coletivo e reafirmação de uma identidade cultural, o caso de Terra sonâmbula. Logo, é a palavra a responsável por traduzir o sujeito de forma efetiva nos dois contextos.

No entanto, essa força se desdobra de maneiras diferentes nos dois contextos. A literatura africana encontra na oralidade a força vital que a palavra oferece, de modo que manter os traços de oralidade significa também manter-se vivo, manter viva sua essência identitária. A compreensão do mundo na cultura africana se dá por meio da palavra falada, daí a dificuldade em transmitir o poder de criação da palavra à escrita. Tal desdobramento se dá em oposição ao texto clariceano, essencialmente escrito e cuja palavra extrapola os limites da língua escrita de forma distinta do propósito literário póscolonial africano. 
Além disso, a literatura africana pós-colonial nasce da necessidade de construir um elo entre membros de uma coletividade despedaçada pelo propósito colonizador europeu, ao passo que a literatura de Clarice é intimista, mas também precisa estabelecer um elo entre seu eu-lírico, seu leitor e os conflitos essencialmente humanos que marcam sua obra. Assim, a força da palavra representa, para Clarice, uma forma de investigar a essência humana, e nisso consiste sua dificuldade em usar a linguagem dentro de uma lógica convencional, já que aquilo que é sentido não pode ser meramente descrito; do mesmo modo, a necessidade de manter a cultura oral dentro da produção escrita representa a dificuldade dos escritores africanos, sendo que, ao longo dessas tentativas, ambos se aproximam por encontrarem na palavra a única força ou instrumento que permite sua existência, resistência e expressão.

Esta pesquisa buscou, inicialmente, encontrar categorias comuns por meio das quais essa força se manifestava. Feito isso, procurou-se demonstrar de que maneira tais categorias se apresentam em ambas as obras, individualmente. Em seguida, fez-se uma análise comparativa das duas obras, aproximando-as e diferenciando-as.

Esta análise torna-se relevante porque, conhecido o histórico de desvalorização da cultura africana, o estudo sobre a construção de literatura escrita desse povo, pautada em valores europeus, aproxima sua produção de padrões valorizados pela hegemonia colonizadora, tais como os padrões que encontramos em Clarice. Assim, na medida em que desvelamos semelhanças para o uso da língua nesses dois contextos, encontramos também validação por parte dos colonizadores para as características exclusivamente africanas, agora pautadas, por exemplo, na grafia, cuja ausência foi utilizada como motivo para descaso em relação à produção literária originalmente oral dos povos africanos. Além disso, percebe-se, aqui, o valor da palavra dentro de contextos políticos, já que a 
mesma língua que foi utilizada como instrumento de dominação é revertida em instrumento de libertação pelos povos colonizados.

O presente trabalho se baseia numa pesquisa qualitativa, conforme Bogdan e Biklen (1994), nascida da leitura de Clarice Lispector e de Mia Couto, onde se vê o processo de valorização da palavra como força criadora. As marcas desta força impressas nas obras foram objeto deste trabalho, considerando o contexto político em que se insere Terra sonâmbula, de Mia Couto, e as inúmeras possibilidades a serem exploradas na narrativa de $A$ hora da estrela, de Clarice Lispector.

Assim foram encontradas as categorias humanização e força de previsão que a palavra desenvolve nos dois textos.

É preciso enfatizar que "a categorização, por si mesma, não esgota a análise. É preciso que o pesquisador vá além, ultrapasse a mera descrição, buscando realmente acrescentar algo à discussão já existente sobre o assunto focalizado" (MENGA E ANDRÉ, 1986, p. 49). Isto implica demonstrar a criação de "conexões e relações que possibilitem a proposição de novas explicações e interpretações" (op.cit. p. 49), no caso, a noção da força da palavra.

\section{A força da palavra em Terra sonâmbula, de Mia Couto}

Terra sonâmbula é um romance que surge no contexto pós-colonialista de Moçambique, de modo a ser parte do que constrói não só o cânone literário, mas também a materialização da moçambicanidade. Além disso, o livro ganha protagonismo 
porque "articula duas épocas muito próximas, porém profundamente fraturadas pela formulação e diluição do sonho da independência" (MELONI, 2015, p. 279).

É importante lembrar que

A desilusão com a ideia coletivista de independência perante a metrópole e a tensão dos conflitos fratricidas que nortearão a disputa pelo poder são a tônica do cenário social e político das ex-colônias portuguesas na África. Em Moçambique, não era diferente. O fim da utopia e o trauma de uma guerra em que o inimigo passa a ser seu próprio irmão consolidam a nação fracionada e enfraquecida pelos anos de guerra contra o colonizador e o início de um novo confronto. Nesse sentido, o cenário do romance de Mia Couto não poderia ser outro, senão uma terra em transe, destruída física e oniricamente (MELONI, 2015, p. 279).

Portanto, Mia Couto chama atenção do leitor, especialmente o leitor moçambicano, para "uma visão daquela terra, [que] em tais desmandados maus tratos, era um espinho de sangrar seus todos corações" (COUTO, 2015, p. 72, explicação acrescentada). Assim, temas como as consequências político-econômico-sociais da guerra civil no contexto pós-colonial são evidenciados ao longo do livro, no intuito, também, de tirar a população do transe, do sonambulismo político em que viviam. Por meio da escrita daquilo que representa sua identidade e realidade, Mia Couto tende a provocá-los a, quem sabe, agir em favor da para construção de uma nacionalidade entre os Moçambicanos, que pode uni-los, conforme Meloni (2015):

A construção de uma linguagem híbrida, que desconstrói a estrutura da língua do colonizador, minando-a por dentro com as línguas locais e os falares do português naqueles espaços [...] será uma das principais temáticas da literatura deste período, visto que construir uma nova linguagem ou ratificar o português popular falado pelos nativos 
atravessados pelas línguas locais era uma das formas mais fortes de resistência cultural (MELONI, 2015, p. 121).

Sendo assim, a força de criação da palavra se manifesta, nesse período, e nesta obra, por ser capaz de criar uma língua dentro da língua, isto é, por criar a moçambicanidade do colonizado dentro da língua portuguesa, do colonizador.

Enfatiza-se aqui a força de criação da palavra não apenas pela subversão sintática ou pelos neologismos, tradicionais no estudo da obra de Mia Couto, mas pela força humanizadora da palavra do autor e pela força de previsão ou concretização desta palavra, a seguir elucidadas. No primeiro capítulo do diário de Kindzu, o rapaz explica como a guerra afeta sua família, cuja desintegração começa a acontecer a partir da sabedoria e previsão de seu ente mais velho, a ser desvelada no próximo tópico, e, depois, pela desumanização de um dos personagens, já que, confiante na previsão de que o menino irá morrer pela guerra, o pai de Kindzu decide que o filho mais novo, Junhito, deveria viver escondido no galinheiro, visto que "galinha era bicho que não despertava brutais crueldades" (COUTO, 2015, p. 17), a fim de protege-lo da ameaça de guerrilheiros durante a guerra civil.

O que chama atenção neste trecho, porém, é que na medida em que "Junhito se foi alonjando de nossas vistas" (COUTO, 2015, p. 17), ele vai tomando, de fato, forma de galinha, animalizando-se, por meio da fantasia que envolve toda obra. Na medida em que convivia com os animais, Junhito realmente mudara "alma e corpo, na aparência de galinha" (COUTO, 2015, p. 17), de modo que "depois, Junhito já nem sabia soletrar as humanas palavras. Esganiçava uns cóóós e ajeitava a cabeça por baixo do braço. E assim se adormecia" (COUTO, 2015, p. 18). 
Dessa forma, a perda da habilidade de dizer "humanas palavras" traz a perda de vida (humana) a que esta família foi submetida em meio ao desgaste da guerra.

No outro núcleo, quando, ao encontrar os diários de Kindzu perdidos no ônibus, Muidinga torna-se leitor ávido desses escritos, estes são capazes de tornar a fuga e a vida miserável mais suportáveis, dado que oferecem distração para a brutalidade da guerra. Movido pelo encorajamento que encontra nos diários, o menino "com um pequeno pau rabisca na poeira do chão..." (COUTO, 2015, p. 36) e choca-se, imediatamente, ao dar-se conta de que conseguia escrever: "Afinal, ele também sabia escrever? Averiguou as mãos quase com medo. Que pessoa estava em si e lhe ia chegando com o tempo?" (COUTO, 2015, p. 36).

Este trecho ilustra de maneira muito lúdica como a humanização acontece por meio da palavra, já que até redescobrir sua capacidade de ler e escrever, o menino se esquece completamente de que havia uma pessoa em si, e é somente quando reencontra essa habilidade que a pessoa "Ihe chega", isto é, que ele se humaniza de novo.

Com isso, a palavra surge em meio à desumanização provocada pela guerra como o único instrumento de humanização para Tuahir e Muidinga. No entanto, Mia Couto demonstra a universalidade da possibilidade de humanização da palavra quando estes dois personagens encontram o velho Siqueleto em sua jornada.

Siqueleto, em sua loucura, traz à tona o desejo africano de reconstruir seu povo que morria durante a guerra. Esse desejo fica evidenciado no trecho:

- Ele diz que nos vai semear.

- Semear?

- Não sabe o que é semear? É isso que nos vai fazer. Ele quer companhia, quer que nasça mais gente (COUTO, 2015, p. 63). 
No entanto, importa chamar atenção para o fato de que semear gente, no contexto aqui apresentado, só é possível por meio da força da palavra.

Por um buraco da rede Muidinga consegue retirar um braço. Apanha um pau e escreve no chão.

- Que desenhos são esses?, pergunta Siqueleto.

- É o teu nome, responde Tuahir.

- Esse é o meu nome?

O velho desdentado se levanta e roda em volta da palavra. Está arregalado. Joelha-se, limpa em volta dos rabiscos. Ficou ali por tempos, gatinhoso, sorrindo para o chão com sua boca desprovida de brancos. Depois, com voz descolorida trauteia uma canção. Parece rezar. Com aquela cantoria Muidinga acaba por adormecer. Não faz ideia quanto tempo dorme. Porque desperta em sobressalto: o brilho de uma lâmina relampeja frente a seus olhos. $O$ velho Siqueleto armaneja uma faca.

\section{- Andam comigo!}

Solta Tuahir e Muidinga das redes. São conduzidos pelo mato, para lá do longe. Então, frente a uma grande árvore, Siqueleto ordena algo que o jovem não entende.

- Está mandar que escrevas o nome dele.

Passa-lhe o punhal. No tronco Muidinga grava letra por letra o nome do velho. Ele queria aquela árvore para parteira de outros Siqueletos, em fecundação de si. Embevecido, o velho passava os dedos pela casca da árvore. E ele diz:

- Agora podem-se ir embora. A aldeia vai continuar, já meu nome está no sangue da árvore (COUTO, 2015, p. 66-67).

Há o sincretismo da força vital e humanizadora da palavra no sentido palavra-serhumano e no sentido palavra-cultura africana, pois quando Muidinga escreve o nome do velho Siqueleto na árvore, a palavra dá a vida para o velho, de modo que, no parágrafo seguinte, ele morre em corpo, mas permanece vivo, porque já está escrito "no sangue da árvore". Além disso, mesmo que não soubesse escrever, a grafia, dada pelos europeus, de seu nome, emprestada ao contexto cultural africano, no ritual descrito pelo trecho, confere a manutenção de sua existência, seja pela figura de um velho africano, detentor e responsável pela transmissão de sua cultura, que aqui é eternizado, seja na crença dele 
(partilhada pelos entes de sua tribo), pois o simples escrever na árvore permite tal eternização.

Tais reflexões levam a compreender a influência da palavra do colonizador português sobre o colonizado africano. Mia Couto fala sobre isso quando Kindzu, em seu diário, recorda-se das lições que aprendia com o pastor Afonso, com quem "ganha esta paixão das letras, escrevinhador de papéis como se neles pudessem despertar os tais feitiços que falava o velho Taímo" (COUTO, 2015, p. 23). Aqui há mais da força humanizadora, se observarmos que, primeiramente, o pastor é uma figura de representatividade europeia/colonizadora em meio aos africanos, com a religião cristã e a alfabetização em língua portuguesa; e, depois, que o velho Taímo era o pai de Kindzu, africano, representante do velho sábio, conhecedor da cultura, mitos e feitiços africanos.

Logo, ainda que o intuito do pastor europeu fosse catequizar os africanos na língua e cultura europeias, a força humanizadora da palavra, ainda que escrita em língua portuguesa, manifesta-se ao despertar em Kindzu a intenção de usá-la de acordo com sua africanidade, em seus mitos e "feitiçarias", pois ele a utiliza como instrumento de valorização da cultura africana, antes desvalorizada pelo seu caráter oral em detrimento da grafia. Agora, porém, sua africanidade estava escrita.

Além disso, ao africanizar a língua portuguesa, uma vez que o autor escolhe registrar as palavras escritas conforme utilizadas pelos falantes africanos, Mia Couto está "criando histórias de reaver este mundo onde não cabemos" (COUTO, 2015, p. 153), isto é, reavendo para os africanos a aceitação de sua construção cultural, já que eles não "cabiam" nos padrões pelos europeus propostos.

Ademais, os falares africanos escritos em língua portuguesa estão civilizando, isto é, humanizando, também os mitos, cultura e modo de viver deles, até então desprezados 
pelos europeus, que consideravam essa cultura não-civilizada, desumana. Aqui, portanto, a força de criação da palavra consiste na possibilidade de reverter o instrumento de exploração do colonizador contra ele mesmo, por meio da construção de uma identidade africana dentro da língua portuguesa, que outrora foi utilizada com um único intuito: ser instrumento de dominação.

Na primeira narrativa do diário, encontramos Kindzu refletindo acerca de como a guerra se aproximara de sua família, fazendo com que eles também enfrentassem a fome e a pobreza e, a partir dessas, como a guerra fez com que eles mudassem, desumanizando-se (COUTO, 2015). Sobre esta temática, há algumas ressalvas a serem feitas. Manifesta-se, logo no primeiro capítulo da perspectiva de Kindzu, pela primeira vez, a força de criação da palavra.

De manhã, nossa mãe nos chamou. Nos sentámos, graves. Meu pai tinha o rosto no peito. Ainda dormia? Ficou assim um tempo como se esperasse a chegada das palavras. Quando finalmente nos encarou quase não reconhecemos.

- Alguém de nós vai morrer.

E logo adiantou razões: nossa família ainda não deixara cair nenhum sangue na guerra. Agora, a nossa vez se aproximava. A morte vai pousar daqui, tenho a máxima certeza, sentenciou o velho Taímo (COUTO, 2015, p. 17).

Esse trecho traz a profecia do pai de Kindzu, e suas palavras, para a família e para Kindzu, têm tanta significação que os personagens transformam sua vida a partir do dito. Fica decidido que o irmão mais novo, Junhito, deverá viver no galinheiro, para se esconder dos guerrilheiros que, conforme a previsão, viriam buscar o menino.

Na cultura africana, compreende-se "a palavra como força motriz de todo o imaginário cultural" (MELONI, 2015, p. 29), de modo que a palavra, dita como profecia, 
pode potencializar as forças imaginativas desse povo de forma muito mais significativa que para o povo ocidental, dado que "as culturas daqueles espaços [africanos] sempre valorizaram a palavra dita e não escrita" (MELONI, 2015, p. 13), palavra esta que é "catalisadora das forças naturais, dos sentimentos humanos, das situações incomuns e corriqueiras" (MELONI, 2015, p. 11).

Essa perspectiva também fica clara quando Kindzu, abalado pela recente morte do pai, o desaparecimento do irmão, a loucura da mãe, vê, na desintegração de sua família, também uma forma de ele estar morrendo. Sem saber o que fazer, decide consultar um sábio da sua aldeia. Nota-se aqui a figura do velho sábio, que perpassa toda a literatura africana como guardião da cultura original, responsável por transmiti-la; e a força, portanto, o impacto que a palavra-previsão tem sobre Kindzu e o enredo da trama:

Segui o conselho dos anciãos evitando o assunto dos naparamas. 0 nosso adivinho se iria sentir magoado de não saber mexer em meus pedidos. Me calei, ouvidor de seus demorados conselhos.

- Te vais separar dos teus antepassados. Agora, tens de transformar num outro homem (COUTO, 2015, p. 30).

Somente após a consulta com o velho detentor da sabedoria Kindzu toma uma decisão acerca do seu próprio destino, e a história ganha corpo, visto que daqui para frente o enredo irá desdobrar-se em torno de sua viagem, sua transição, seu caminho.

\section{A força da palavra em A hora da estrela, de Clarice Lispector}


Conforme proposto por Sartre (2004), o sentido do texto se constrói no momento da leitura, ou a segunda etapa da escrita do livro, que o leitor termina de construir no momento em que lê, nem sempre segundo a intenção do autor, mas sempre seguindo a materialidade do texto. Em A hora da estrela, por meio do narrador Rodrigo S.M., Clarice ratifica a consciência da contribuição do leitor para a composição do texto quando o narrador se indaga acerca do resultado daquilo que escreve "como que estou escrevendo na hora mesma em que sou lido" (LISPECTOR, 1998, p. 12).

A força da palavra manifestada nesse livro é humanizadora, transformadora e um canal para materialização dos sentimentos humanos, bem como vimos em Terra sonâmbula, de Mia Couto. Seguem exemplos de como isso acontece, nas categorias força de transformação da palavra e força de previsão da palavra.

Macabéa, personagem central da obra, é desumanizada por sua ignorância e falta de beleza, e mais do que isso, por sua falta de consciência de si mesma e até do mundo a seu redor. O narrador, Rodrigo S. M., chega a descrevê-la como invisível, "ninguém olhava para ela na rua, ela era café frio" (LISPECTOR, 1998, p. 27); ou malquista, dispensável, “a pessoa de quem falarei mal tem corpo para vender, ninguém a quer, ela é virgem e inócua, não faz falta a ninguém" (op. cit. p. 14).

Sendo assim, escrever sobre Macabéa, contar sua história, é uma forma de humanizá-la. Sobre isto, escreve Gabriela Lírio Gurgel:

O nada se refaz na linguagem da personagem que, por tanta ausência, pela falta de nomeação das coisas, pela compreensão singular da realidade, a faz experimentar uma espécie de litígio com o mundo e com os outros. Uma imanência de solidão, uma impossibilidade de comunicação mais clara e direta. Macabéa é uma abertura para um estado de vazio longo, um final de frase continuado; intermitente. Não é 
só virgem de corpo, é virgem de linguagem, é virgem de palavra [...] (GURGEL, 2001, p. 55).

Na medida em que Ihe falta conhecimento, consciência e, sobretudo, a palavra, falta-lhe também interação dela consigo mesma e com o mundo, o que justifica o litígio. Se é pela linguagem que compreendemos e significamos o mundo e damos nomes aos seres, Macabéa era solitária porque não sabia se comunicar, porque era "desaprendida" da linguagem. Ela se torna desumana porque sua virgindade de palavras a isola. Portanto, dar palavras à Macabéa, mesmo que seja a voz emprestada de Clarice, ou de Rodrigo S.M., significa dar-Ihe vida, isto é, humanidade.

Escrever sobre esta personagem torna-se também um ato político, dado que a palavra de Rodrigo S.M. empresta à Macabéa a voz que suas condições de vida, nordestina, pobre, pouco escolarizada, sempre lhe negaram. Atentar-se para ela é trazer à tona sua "compreensão singular da realidade" (GURGEL, 2001, p. 55), um modo de vida que não se conhece ou para o qual, em geral, não se olha, solitário, macabéico.

Porém, a humanização não ocorre apenas com Macabéa, mas com o próprio Rodrigo:

E assim se passava o tempo para a moça esta. Assoava o nariz na barra da combinação. Não tinha aquela coisa delicada que se chama encanto. Só eu a vejo encantadora. Sé eu, seu autor, a amo. Sofro por ela. E só eu é que posso dizer assim: 'que é que você me pede chorando que não the dê cantando"? Essa moça não sabia que ela era o que era, assim como um cachorro não sabe que é cachorro. Daí não se sentir infeliz' (LISPECTOR, 1998, p. 27).

Na medida em que Rodrigo busca e encontra meios de descrevê-la, ele se torna também compassivo, compreensivo, solidário. Visto isso, fica fácil entender de que 
maneira somente a força transformadora da palavra permite o encontro, ou talvez a capacidade de humanização tanto de Rodrigo quanto de Macabéa.

Há, entretanto, uma aproximação entre Rodrigo e Macabéa, a qual se dá exatamente na palavra-não no fato de que um escreve e a outra é escrita, mas no modo como a palavra afeta a existência de cada um. Ambos se envolvem e lutam com a palavra, embora somente Rodrigo seja consciente disso (FERREIRA-PINTO, 1987, p. 22).

Segundo o narrador, Macabéa "só vagamente tomava conhecimento da espécie de ausência que tinha de si em si mesma" (LISPECTOR, 1998, p. 24), o que explica a consciência de Rodrigo em oposição à "desconsciência" de Macabéa. Nela, a força da palavra se manifesta como fraqueza, por sua ausência.

O nome Macabéa, ao fazer "uma alusão simbólica aos Macabeus, figuras do Livro de Apócrifo que eram modelos de firmeza e resistência" (VIEIRA, 2012, p. 126), constrói um paradoxo: Macabéa é o absoluto oposto de firmeza e resistência; mas ao insistir em existir incomodando o mundo, pelo vazio e pela mornidão que representava, sua humanidade (embora refutada e ratificada inúmeras vezes ao longo da obra) também é resistência.

É também por meio da "escrição", ou do "escrevimento", de Macabéa que o narrador encontra na palavra seu caráter humanizador de si para si mesmo:

Escrevo por não ter nada a fazer no mundo: sobrei e não há lugar para mim na terra dos homens. Escrevo porque sou um desesperado e estou cansado, não suporto mais a rotina de me ser e se não fosse a sempre novidade que é escrever, eu me morreria simbolicamente todos os dias (LISPECTOR, 1998, p. 21). 
Assim, a força transformadora da palavra consiste em criar possibilidades outrora inimagináveis, seja pela humanização de uma personagem absolutamente isenta de humanidade (Macabéa), seja pela renovação do espírito e da força de Rodrigo.

Por isso nos chama atenção a nítida consciência de Clarice para o fato de que a palavra está exercendo seu potencial transformador: “O meu material básico é a palavra. Assim é que esta história será feita de palavras que se agrupam em frases e destas se evolua um sentido secreto que ultrapassa palavras e frases" (LISPECTOR, 1998, p. 15).

O "sentido secreto" assim o é porque cada leitor encontrará, no texto literário, um sentido particular, único, o próprio potencial transformador da palavra, co-construindo o texto, conforme proposto por Eco (1986).

Por fim, Macabéa esbarra com a força de previsão ou de concretização da palavra ao consultar uma vidente, Madama Carlota, em cujas palavras a personagem encontra o consolo que ao longo de toda sua vida lhe foi negado:

- Macabéa! Tenho grandes notícias para Ihe dar! Preste atenção, minha flor, porque é de maior importância o que vou lhe dizer. É coisa muito séria e muito alegre: sua vida vai mudar completamente! E digo mais: vai mudar a partir do momento em que você sair da minha casa! (LISPECTOR, 1998, p. 76).

Trata-se aqui da força com que a palavra atinge aquele que a escuta, aquele a quem toca, e este, sim, atingido pela força que o tocou, catalisadora de sentimentos, utiliza a palavra como instrumento de construção de atitudes, concretizando sua força.

Por isso, mesmo que a previsão da cartomante fosse falsa, há, ainda assim, e de fato, uma concretização dessa previsão na medida em que Macabéa se apodera da força da palavra emitida pela Madama: 
Num súbito ímpeto (explosão) de vivo impulso Macabéa, entre feroz e desajeitada, deu um estalado beijo no rosto da madama. E sentiu de novo que sua vida já estava melhorando ali mesmo: pois era bom beijar (LISPECTOR, 1998, p. 78).

Macabéa não sabia "que ela era o que era, assim como um cachorro não sabe que é cachorro. Daí não se sentir infeliz" (LISPECTOR, 1998, p. 27); visto isso, no encontro desta personagem com as palavras de Madama Carlota, a nordestina encontra o desejo que tinha de ter consciência de si e de ser feliz, o que nunca the fora permitido justamente pela sua ausência de consciência e de linguagem. Assim, de novo lhe é emprestada uma palavra, agora a palavra de Madama Carlota.

Além disso, é nítido que, para Clarice, a palavra detém a força de previsão pois, ainda que ciente da incapacidade desta mesma palavra dar conta de todos os mais amplos significados, sentimentos e sentidos, ela a escolhe - a palavra - como único instrumento para a tentativa de "fazer caber" sua mais ampla ou mais "incabível" significação, sua essência: "a minha vida, a mais verdadeira é irreconhecível, extremamente interior e não tem uma só palavra que a signifique." (LISPECTOR, 1998, p. 11).

A semelhança entre as obras pode ser encontrada em diversos momentos. Se considerarmos que a palavra política, em sentido amplo, pode significar a luta pelo poder, ambas manifestam a força política da palavra, visto que dar voz à Macabéa, bem como à Kindzu e ao povo africano, significa conferir poder àqueles que são social, cultural e politicamente marginalizados.

Macabéa, a nordestina imigrante, pobre, "deslinguajada". Kindzu, um fugitivo do seu próprio povo, que sofre as consequências de uma guerra provocada por ações 
primeiras de governantes colonizadores (os detentores do poder). A partir da visibilidade que a palavra lhes deu, podemos pensar politicamente, pois podemos considerar se a forma como nossos governantes e nossa sociedade tratam as Macabéas, Kindzus, Tuahirs e Muidingas está de acordo com os princípios de uma sociedade justa e governada para o bem de todos. A palavra, em ambos os livros, tem força política pois confere evidência aos negligenciados.

\section{Considerações finais}

O estudo da força da palavra nas obras escolhidas tem uma importante premissa humanizadora; o simples contato com personagens que configuram tipos sociais excluídos permite ao leitor um novo olhar para questões sociais e políticas que precisam ser revistas.

A aproximação da literatura prestigiada de Clarice Lispector de Mia Couto e as questões africanas pode permitir também a humanização, por meio da quebra de um preconceito por parte dos alunos, que muito pouco ou nada sabem sobre os mitos, tradições e valores culturais africanos.

A literatura comparada permite uma análise mais cuidadosa aos contextos de ambas as obras, e a valorização da própria literatura, trazendo à luz um objetivo social semelhante ao cotidiano dos alunos, muitas vezes marginalizados ou excluídos.

O registro escrito da cultura africana em Mia Couto mostra o poder de subversão da palavra na língua do colonizador quando usada contra ele, pelo colonizado. A palavra 
se torna instrumento de ascensão social, na medida em que valoriza a cultura africana, e em que oferece domínio sobre si mesmo e o mundo, como faltava em Macabéa.

\section{Referências}

BOGDAN, Roberto C.; BIKLEN, Sari Knopp. Investigação qualitativa em educação.

Tradução Maria João Alvarez, Sara Bahia dos Santos e Telmo Mourinho Baptista. Porto: Porto Editora, 1994.

COUTO, Mia. Terra sonâmbula. Companhia das Letras: São Paulo, 2015.

ECO, Umberto. Lector in fabula: a cooperação interpretativa nos textos narrativos. Trad.: Attílio Cancian. São Paulo: Perspectiva, 1986.

FERREIRA-PINTO, Cristina. A luta pela auto-expressão em Clarice Lispector: o caso de A Hora da Estrela. Mester, v. 16, n. 2, 18-24, 1987.

GURGEL, Gabriela Lírio. A procura da palavra no escuro: uma análise da criação de uma linguagem na obra de Clarice Lispector. 7 Letras: Rio de Janeiro, 2001.

LISPECTOR, Clarice. A hora da estrela. Rocco: Rio de Janeiro, 1998.

MENGA, Ludke; ANDRÉ, Marli E. D. A. Pesquisa em educação: abordagens qualitativas. EPU: São Paulo, 1986.

MELONI, Otávio Henrique. Aula 1 - Introdução à narrativa dos países africanos de língua portuguesa. In: MELONI, Otávio Henrique; FRANCO, Roberta Guimarães. Literaturas africanas II. Rio de Janeiro: Fundação Cecierj, 2015. p. 8-29.

SARTRE, Jean-Paul. Que é a literatura? Tradução Carlos Felipe Moisés. 3. ed. São Paulo: Ática, 2004.

VIEIRA, Nelson H. Identidade equivocada/Mistaken Identity: Clarice Lispector e a ética de alteridade. Disponível em: <https://publications.iai.spk-

berlin.de/servlets/MCRFileNodeServlet/Document_derivate_00000479/BIA\%20147\%20Vi eira.pdf>. Acesso em: 13 out. 2019 (2012). p. 119-133. 
Gabriela de Castro Maciel Oliveira e Maria da Conceição Vinciprova Fonseca

Recebido em 31 de agosto de 2019.

Aceite em 07 de outubro de 2019. 